\title{
LA INDEPENDENCIA DE CENTROAMÉRICA Y LA INFLUENCIA EXTRANJERA
}

\author{
THE INDEPENDENCE OF CENTRAL AMERICA \\ AND THE FOREIGN INFLUENCE
}

\author{
Carlos Puente Martín ${ }^{1}$ \\ ORCID: 0000-0003-1180-4752
}

\section{RESUMEN}

El presente artículo expone la evolución del proceso de independencia de los territorios de las colonias del Imperio español en América Central. No solo se sugiere la influencia de las ideas liberales en Europa, procedentes de la Revolución Francesa de 1789, sino también el ejemplo de la independencia de Estados Unidos.

El proceso independentista en Centroamérica fue un movimiento pacífico en contraste con los enfrentamientos militares con las tropas realistas de la monarquía española en otras regiones. Se relata la importancia de la participación de militares y políticos en la lucha por la independencia, pero también del estamento religioso más básico, es decir de los curas. Para ello, se acude a los textos de las Actas de independencia de 1821 y de 1823 y al Acta de la Anexión de Centroamérica al Imperio mexicano para valorar el papel que desempeñó la voluntad popular durante el proceso emancipador frente a la influencia de otros Estados. Una reflexión sobre la influencia de la política de Estados Unidos y, en particular, de la Doctrina Monroe, marca la diferencia entre independencia y soberanía en el proceso independentista de las provincias centroamericanas.

\section{ABSTRACT}

The main target of the article is to understand the evolution of the independence process of the colonies of the Spanish Empire in Central America. It is suggested not only the influence of liberal ideas from Europe after the French Revolution of 1789 but also the example of the independence of the United States.

The independence process in Central America was a peaceful movement in contrast to the military confrontations with the royalist troops of the Spanish Monarchy elsewhere. The importance of the participation of the military and politicians in the struggle for independence is underlined, but the participation of the most basic religious establishment, the priests, was of great importance. The legal texts of the Independence Acts of 1821 and 1823 and the Act of the Annexation of Central America to the Mexican Empire are used to assess the role played by the popular will during the independence process against the influence of other foreign States. A reflection on the influence of the United States foreign policy and, especially, of the Monroe Doctrine marks the difference between independence and

1 Universidad de Viena. Profesor visitante-conferenciante. Doctor en Ciencias Económicas. Correo electrónico: cpmartin28@gmail.com 
La importancia geopolítica de la región atrajo el interés no solo de las potencias europeas, en particular de Gran Bretaña, sino también de Estados Unidos durante el período que ocupa este artículo. La inestabilidad política, económica y social que siguió al proceso de independencia fue aprovechada por el gigante estadounidense para obtener una vía que permitiera la comunicación entre las costas del Atlántico y del Pacífico, lo que contribuía con la expansión de un nuevo imperialismo.

Palabras clave: Centroamérica; Doctrina Monroe; geopolítica; Imperiomexicano; independencia absoluta; potencias sovereignty in the independence process of the Central American provinces.

The geopolitical importance of the region attracted the interest not only of the European powers, especially Great Britain, but also the United States during the period covered by this article. The political, economic, and social instability that followed the independence process was used by the North American giant to open a waterway that would allow the communication between the Atlantic and Pacific coasts, contributing to the expansion of a new kind of imperialism.

Key words: Absolute Independence; Central America; geopolitics; Mexican empire, Monroe Doctrine, powers

\section{Introducción}

Con la llegada de los españoles a América se trasplantó a las regiones bajo su influencia la estructura política, social, religiosa, cultural y económica que existía en la península ibérica, con determinadas adaptaciones, como había sucedido con otras civilizaciones antiguas en el mar Mediterráneo al instalarse en nuevos territorios. Los estamentos que ostentaban el poder en España fueron reproducidos en el continente americano. Por lo tanto, no fue extraña la existencia de las mismas virtudes y defectos, con sus abusos, en ambas orillas del océano Atlántico, que permaneció con sus naturales adaptaciones a lo largo de los siglos. La Capitanía General de Guatemala ${ }^{2}$, no fue una excepción. Guatemala se había erigido en el centro político y cultural de la Capitanía, contando con la Universidad de San Carlos, la tercera universidad fundada en el continente. Por razones obvias, el presente artículo no abordará la independencia de Panamá pues lo fue de Colombia y no del Imperio español.

Mucho antes de que las Trece Colonias de América del Norte inspirara los movimientos insurgentes del siglo XIX en la América hispana, ya se habían producido brotes de insurrección en las colonias, como el protagonizado por el cacique mestizo peruano Tupac Amaru a finales del siglo XVIII, que pretendió restaurar el Imperio de los incas. Y en el virreinato de Nueva Granada la rebelión de los Comuneros ${ }^{3}$, cuya cabeza visible fue el terrateniente Juan Francisco Berceo, erigido en general de la insurrección, había sido otro

2 La Capitanía General de Guatemala estaba constituida por los actuales territorios de Guatemala, Belice, Costa Rica, Honduras, Nicaragua, El Salvador, el Estado mexicano de Chiapas y las provincias panameñas de Chiriquí y Bocas del Toro.

3 La rebelión de los Comuneros fue un movimiento contra España, que tuvo lugar el 16 de marzo de 1781, durante el gobierno del rey Carlos III. 
antecedente próximo a Centroamérica, aunque traía causa en reivindicaciones económico-fiscales, a propósito de un edicto de la Corona española que imponía nuevos tributos.

A principios del siglo XIX se siente con fuerza la influencia del desarrollo de Estados Unidos, independiente de Inglaterra desde 1776, los movimientos revolucionarios en Francia y la búsqueda de una fórmula que fortaleciera el principio de la soberanía nacional en la metrópoli española. Además, como subraya el profesor Jaime Vicens Vives

la causa básica del movimiento de emancipación de las colonias españolas en América, hay que buscarla en la formación de una conciencia revolucionaria que sirvió los intereses económicos y políticos de la burguesía colonial... En las colonias se había formado una nueva casta social, la de los criollos enriquecidos por el comercio o por la propiedad dominical, los cuales se veían alejados de las cosas públicas por la burocracia española. (Vicens, 1976: pp. 277-278)

Muy pocos analistas o historiadores han comprendido el verdadero papel geopolítico que desempeñaron los movimientos independentistas de las colonias españolas en el continente americano, dentro del marco de intereses de las grandes potencias europeas y el naciente imperio estadounidense, aspecto que motiva la redacción de este artículo, el cual se ha construido a partir del análisis de contenido de fuentes primarias como las actas de independencia, así como de bibliografía sobre la materia, producida tanto en la época estudiada como publicaciones de data más reciente, donde el uso de las citas será importante para ejemplificar y contextualizar los antecedentes y alcances de los procesos de independencia, en particular, el caso Centroamericano.

En la independencia de las colonias españolas de América existieron algunos elementos comunes que la diferenciaron del modelo estadounidense, en el cual intervino una élite anglosajona, con una carga religiosa y defensora de las libertades individuales heredadas de Gran Bretaña. Por el contrario, en la América hispana la "aristocracia criolla" asumió un papel protagónico con participación ocasional de la población indígena (Diccionario Enciclopédico Salvat, 1981: p. 57). ${ }^{4}$

Pero el elemento diferenciador más significativo fue la participación directa del estamento religioso en los movimientos revolucionarios. Los curas son

4 Diccionario Enciclopédico Salvat, Salvat Universal, Tomo 2, Barcelona 1981, p. 57. Muchos de los datos históricos utilizados en este trabajo han sido extraídos de esta obra con la redacción oportuna. 
personajes activos en la independencia de las colonias americanas del Imperio español, tal y como se analizará en las páginas siguientes.

El proceso independentista en Centroamérica transcurre de forma diferente al de otras regiones del Imperio español en América. La separación de las provincias del istmo centroamericano de España se produce de forma pacífica, quizá porque los movimientos revolucionarios violentos tienen a próceres surgidos de las grandes ciudades. La invasión de España por Napoleón Bonaparte y el vacío de poder causado por la ocupación francesa pusieron de relieve las deficiencias existentes en las provincias ultramarinas.

Los intereses imperialistas de Inglaterra y Estados Unidos no fueron ajenos y su ayuda a los movimientos emancipadores no era desinteresada, pero sí meditada. Centroamérica limitaba al norte con Nueva España y al sur con Nueva Granada pero Gran Bretaña había aumentado su influencia en la región durante la invasión napoleónica de la península ibérica (Renouvin, 1982 y 1990). Por una parte, en la Costa de los Mosquitos, en la región de Honduras a orillas del mar Caribe, aunque por el Tratado de París de 1783, Gran Bretaña había cedido su soberanía en $1787^{5}$; por otra, en el territorio de Belice, en la costa del mar Caribe y rodeado por Guatemala y México, donde el dominio español cesó con la independencia de Centroamérica y se convertiría en una dependencia británica a pesar de las reclamaciones de Guatemala.

Los intereses geopolíticos y económicos de algunas potencias extranjeras comenzaron a hacerse más visibles tras la independencia, situación que hacía más notoria la debilidad de la soberanía real. Parafraseando al Atlas Histórico del Mundo (2011: p. 141), se produciría el "fin de la utopía de Bolívar" con la victoria de las posturas antifederalistas y con la subdivisión de la Gran Colombia en Venezuela, Ecuador y Nueva Granada.

La independencia de Estados Unidos de la metrópoli en 1776 señaló la ruta para otros territorios del continente americano para emanciparse de los imperios europeos. La Revolución Francesa de 1789 proporcionó los fundamentos jurídicos esenciales para hacer realidad la independencia de las tierras americanas de la

5 Como describe Barbara Potthast-Jutkeit (1998: 503): "Sólo al estallar la "Guerra de la oreja de Jenkins" o de la "Sucesión austriaca" en 1739-1740 se estableció el protectorado inglés. En aquel momento las poblaciones inglesas en la Costa de Mosquitos ya tenían un carácter más estable y honorable; el gobierno de Londres, sin embargo, aún tardó hasta fines de la guerra para mandar un teniente gobernador (llamado superintendente) a la costa. El motivo inminente para firmar oficialmente un tratado de protección con los mosquitos fue el deseo de asegurarse el apoyo de los guerreros mosquitos para un ataque a Panamá; no obstante, el objetivo principal de la política británica en Centroamérica, incluyendo la Costa de Mosquitos, siguió siendo el dominio del comercio en la región”. 
tutela europea. La Declaración de los Derechos del Hombre y del Ciudadano del 26 de agosto de 1789, que encabezó la primera constitución francesa de 1791, fueron instrumentos esenciales en la formación de una conciencia de soberanía nacional. Por su parte, la propia Constitución española de 1812, abrió la posibilidad de generar en los territorios ultramarinos un sentimiento de soberanía nacional en las clases dirigentes (Sánchez, 1971).

Sin embargo, pocos estadistas fueron los que se dieron cuenta de que esta situación podría ser un espejismo y la realidad muy corta en lo temporal. Incluso el profesor Adolfo Miaja de la Muela contribuyó a esta confusión académica al amalgamar los conceptos de independencia y soberanía en el contexto del derecho internacional. Miaja no es capaz de separar ambos conceptos jurídicos y describe la situación de los países hispanoamericanos de forma errónea:

La independencia de casi toda la América meridional y central siguió, en período, en perspectiva histórica, muy corto, a la de los Estados Unidos. Sin entrar a dilucidar lo que esta independencia debe a la Doctrina de Monroe, a la política inglesa de Canning, o a las debilidades internas de la Santa Alianza o de la España fernandina, lo cierto es que una veintena de nuevos Estados hacen su entrada en la vida internacional. No importa que en varios de ellos la población aborigen, mestiza y negra forme una mayoría frente a la clase 'criolla' dirigente. Esta clase es blanca y cristiana, y tiene en sus manos la conducción de los nuevos Estados, que adoptan formas constitucionales de inspiración europea, aunque no excluyan estas formas la aparición frecuente de dictaduras. (1968: pp. 23-24)

Así, para comprender cómo fue el proceso de independencia en la región Centroamericana y el papel que jugaron algunas potencias, en particular Estados Unidos, el presente artículo se estructura en tres grandes secciones: primero, una reflexión histórica sobre la independencia de Centroamérica, luego se analiza el papel de la independencia de los Estados Unidos y su influencia en la región y se finaliza con una recapitulación de las principales conclusiones vinculadas con los alcances de las declaraciones de independencias y la materialización de los intereses de potencias externas en la región después de su emancipación formal. 


\section{La independencia de Centroamérica}

Con la invasión de España por los ejércitos de Napoleón Bonaparte y el levantamiento del 2 de mayo de 1808 en Madrid contra el invasor francés, comenzaron a organizarse las Juntas provinciales para sustituir el vacío de poder. En los extremos de la actual Centroamérica, Nueva Granada y Nueva España, los movimientos revolucionarios independentistas tuvieron trayectorias distintas. En el Virreinato de Nueva Granada, la explosión independentista se localizó en las urbes importantes del virreinato pues, como expone el profesor Vicens Vives:

La agitación secesionista se manifestó por vez primera en Quito, donde el 9 de agosto de 1809 los patriotas se apoderaron del poder, destituyendo al presidente Urries y establecieron una Junta, bajo la presidencia del marqués de Selva Negra... Los sucesos de Quito enardecieron a los patriotas de Santa $\mathrm{Fe}$, los cuales, el 20 de julio de 1810, se amotinaron y obtuvieron del virrey Amar la constitución de una Junta de Gobierno... Las ciudades más populosas habían proclamado sus respectivas juntas: Cartagena en mayo; Socorro en julio; Santa María en agosto... El nuevo estado de Cundinamarca, cuya primera carta constitucional fue promulgada el 30 de mayo de 1811, evolucionó rápidamente hacia la ruptura con España y Fernando VII. De hecho, en noviembre de 1811 la revolución estaba consumada. (1976: p. 282)

Por su parte, al norte de Centroamérica, los hechos tuvieron un cariz social y más violento que el ocurrido en el sur, produciéndose un proceso revolucionario que inquietó a la burguesía criolla que se pasó de bando tras el grito independentista de Dolores por los excesos de los independentistas. El militar y sacerdote José María Morelos, comisionado por Miguel Hidalgo, combatió a los realistas con éxito en el sur de México y organizó el Congreso de Chilpancingo que proclamó la independencia de México el 6 de noviembre de 1813. Los hechos iniciales los relata el Vicens Vives de esta forma:

El 9 de agosto de 1808 se constituyó en la capital de Nueva España una Junta presidida por el virrey Iturrigaray, en la que se reflejaron los deseos autonomistas del elemento criollo predominante en el Ayuntamiento... El 15 de septiembre el virrey fue depuesto y la Junta suprimida... Primero en Valladolid y luego en Querétaro brotaron los chispazos de la insurrección. El 16 de septiembre de 1810, el cura párroco de Dolores, Miguel Hidalgo, amotinó a sus feligreses contra las autoridades virreinales. El grito de Dolores halló eco entre las masas indígenas, que se sumaron a los sublevados en una guerra de razas y clases sociales (1976: p. 283). 
El movimiento independentista en Centroamérica puede considerarse que tuvo un sesgo pacífico y fue potenciado por los acontecimientos de la guerra de la Independencia española contra Napoleón en la península ibérica, que había provocado un vacío de poder en las instituciones políticas de la metrópoli. Ante esta situación, se constituyeron Juntas provinciales y la Junta Central instituida en septiembre de 1808. El primer episodio independentista en Centroamérica tuvo lugar en San Salvador, el 5 de noviembre de 1811, dirigido por los religiosos José Matías Delgado y Nicolás Aguilar, que continuó con otros. A este movimiento le siguieron levantamientos en Nicaragua, la Conjuración de Belén y otros actos de 1814 a 1821. El 24 de enero de 1814 se produjo una revuelta popular en San Salvador que terminó en un gran fracaso, con la detención de los organizadores y la muerte de su líder, Santiago de Celis.

La situación en la península ibérica tuvo un paralelismo en la América hispana pues en 1810 fue nombrado Capitán General de Guatemala el reformista José de Bustamante y Guerra, quien representando al gobierno del rey Fernando VII no dudó en rechazar la Constitución de 1812 y sofocar los movimientos independentistas apoyados por los revolucionarios Miguel Hidalgo y Costilla y José María Morelos en la vecina Nueva España. El Capitán General, José de Bustamante, tuvo conocimiento de que algunos independentistas civiles y religiosos acudían a reuniones en el Convento de Belén, organizadas por fray Juan Nepomuceno de la Concepción, con el objetivo de sublevarse y deponer a Bustamante. El resultado de la represión fue el apresamiento de civiles, militares y religiosos. Entre los detenidos figuraba el propio Juan Nepomuceno.

Mientras tanto, en la península ibérica, Napoleón Bonaparte reconoció a Fernando $\mathrm{VII}^{6}$ como rey de España por el Tratado de Valençay, de 11 de diciembre de 1813, quien llegó a la frontera española el 13 de marzo de 1814. El 4 de mayo de ese año promulgó un decreto ${ }^{7}$ restableciendo la monarquía absoluta y derogando la Constitución de 1812.

En 1818 el Capitán General Bustamante y Guerra fue sustituido por el teniente general Carlos Urrutia y Montoya cuya actitud facilitó la actividad de los criollos independentistas tras el restablecimiento de la Constitución de 1812 y el

6 Fernando VII (1784-1833) sucedió a su padre el rey Carlos IV y reinó entre 1808 (parcialmente) y 1833, salvo un breve periodo en 1823. Aunque fue llamado "el Deseado" por las clases populares, en realidad fue el rey más siniestro e ignominioso de la monarquía española, lo que le valió el título de "el rey Felón".

7 El Decreto fue redactado por Juan Gregorio Felipe Ramón de Pérez Villamil y Paredes, político conservador en los reinados de Carlos IV y su hijo Fernando VII, y Miguel de Lardizábal y Uribe, político español nacido en Nueva España, a quien Fernando VII nombró ministro Universal de Indias en 1814 y se opuso a las reformas liberales y a los movimientos independentistas de los criollos en América. 
levantamiento del coronel Rafael del Riego en Cabezas de San Juan (provincia de Sevilla), en 1820. En 1821 le sustituyó el brigadier Gabino Gainza ${ }^{8}$ quien facilitó el camino de los independentistas al aceptar la independencia de Guatemala el 15 de septiembre de 1821. Unos meses antes, el 24 de febrero de ese año, México había declarado su independencia de España tras el triunfo de la revolución y el Plan de Iguala, lo que influyó en los acontecimientos en Guatemala. De hecho Gainza había organizado una reunión con los independentistas de la que surgió el grito de independencia de las provincias que formaban la Capitanía de Guatemala. Cecilio del Valle redactó un documento y el Capitán General hizo lo propio en un manifiesto sobre los deseos de independencia y la forma de elección de los representantes en el Congreso de la nación que establecería la forma del gobierno.

En esa fecha, el 15 de septiembre de 1821, las autoridades políticas y eclesiásticas e independentistas criollas firmaron el Acta de Independencia de la Capitanía de Guatemala, con los territorios de Costa Rica, Guatemala, Honduras, Nicaragua, San Salvador, Comayagua y Chiapas.

\subsection{Acta de Independencia de Centroamérica}

El 15 de septiembre de 1821 se reunieron en el Real Palacio los representantes del gobierno, de la Iglesia católica, del Ayuntamiento, de la Universidad de San Carlos y otros estamentos representativos. Los hechos que se produjeron, tal como se han descrito más arriba, dieron lugar a la firma del documento del Acta de Independencia de la Capitanía General de Guatemala ${ }^{9}$. El resultado de la votación fue de 23 votos a favor de la independencia y 7 en contra. El primer párrafo del Acta describe las intenciones de los allí reunidos:

Siendo públicos e indudables los deseos de independencia del gobierno Español, que por escrito y de palabra ha manifestado el pueblo de esta capital: recibidos por el último correo diversos oficios de los Ayuntamientos Constitucionales de Ciudad Real, Comitan y Tuxtla, en que comunican haber proclamado y jurado dicha independencia y excitan á que se haga lo mismo en esta ciudad: siendo positivo que han circulado iguales oficios á otros Ayuntamientos: determinado, de acuerdo con la Excelentísima Diputación Provincial, que para tratar de asunto tan grave se reuniesen en uno de los salones de este palacio la misma Diputación Provincial, el Ilustrísimo

8 Gabino Gainza y Fernández de Medrano (1753-1825) fue un militar y político español, nacido en Vizcaya. Tras el Congreso Constituyente de 1 de marzo de 1822 presidió la Junta Provisional Consultiva controlando el poder político y militar de la provincia de Guatemala. Fue encarcelado por los independentistas y desterrado a México de donde huyó a Cuba.

9 Véase en: https://web.archive.org/web/20100930160431/http://www.mined.gob.ni/independ2.php 
Sr. Arzobispo, los Señores individuos que disputasen la Excelentísima Audiencia Territorial, el Venerable Señor Deán y Cabildo Eclesiástico, el Escelentísimo Ayuntamiento, el M.I. Claustro, el Consulado y el M.I. Colegio de Abogados, los Prelados Regulares, Jefes y funcionarios públicos: congregados todos en el mismo salón: leídos los oficios expresados: discutido y meditado detenidamente el asunto; y oído el clamor de Viva la Independencia, que repetía de continuo el pueblo que se veía reunido en las calles, plaza, patio, corredores y antesala de este palacio, se acordó por esta Diputación e individuos del Esmo. Ayuntamiento. (Se ha respetado la grafía original).

Y en el punto primero de lo acordado se subraya el firme deseo de independencia del pueblo de Guatemala, aludiendo al Congreso que debe establecerse y, en el punto segundo, se menciona que dicho Congreso deberá estar formado por diputados y representantes para decidir "el punto de Independencia y fijar, en caso de acordarla la forma de gobierno y la ley fundamental que deba regir". Este es un pasaje importante pues una cosa es la independencia y otra muy distinta la forma en que la soberanía se manifiesta. Y no es cuestión baladí pues en las colonias españolas de América del Sur habían surgido dos figuras independentistas que mantenían visiones distintas en cuanto a la forma de gobierno tras la independencia de las vastas regiones españolas situadas al norte del Amazonas y al sur del caudaloso río.

Los dos grandes personajes eran, por una parte, el general José de San Martín, el Protector; y, por otra, el general Simón Bolívar, conocido como el Libertador. En la "Entrevista de Guayaquil" el general San Martín declaraba que

...dejaría bien establecidas las bases del gobierno; que éste no debía ser democrático en el Perú porque no convenía, y últimamente que debería venir de Europa un príncipe aislado y solo a mandar aquel estado“. A lo que el general Simón Bolivar replicó "que no convenía a la América ni tampoco a Colombia la introducción de príncipes europeos porque eran partes heterogéneas a nuestra masa; que Su Excelencia se opondría por su parte si pudiese pero que no se opondría a la forma de gobierno que quiera darse cada Estado, añadiendo sobre este particular Su Excelencia todo lo que piensa con respecto a la naturaleza de los gobiernos, refiriéndose en todo a su discurso al Congreso de Angostura. (Reportaje de la Historia, 1962: p. 464)

Y en la carta que Simón Bolívar dirigió al general F. de P. Santander fechada en Guayaquil el 29 de julio de 1822, donde el Libertador menciona la idea de una gran federación de pueblos: 
El Protector me ha ofrecido su eterna amistad hacia Colombia; intervenir a favor del arreglo de límites; no mezclarse en los negocios de Guayaquil; una federación completa y absoluta aunque no sea más que con Colombia. Debiendo ser la residencia del Congreso Guayaquil; ha convenido mandar un diputado por el Perú a tratar, de mancomún con nosotros, los negocios de España con sus enviados; también ha recomendado a Mosquera a Chile y Buenos Aires para que admitan la federación. (Reportaje de la Historia, 1962: p. 469)

En los puntos 3, 4 y 5 del Acta se establecían las condiciones para el nombramiento de diputados y su número, con la expresa mención de "sin excluir de la Ciudadanía a los originarios de África”. En el punto 6 se imponía la fecha para que la reunión de los diputados debiera ser el 1 de marzo de 1822 . Y en el punto 8 se afirmaba la continuidad de Don Gabino Gainza como Jefe del Gobierno Superior Político y Militar y la organización de una Junta provisional consultiva formada por los miembros de la actual Diputación Provincial. Se hacía una defensa de la religión católica y sus eclesiásticos en el punto 10, como uno de los signos de identidad de Guatemala. En el punto 13 se subraya la obligación de fidelidad y el juramento de independencia del gobierno que se establezca, igual que la Junta provisional y los estamentos de la sociedad civil, religiosa o militar, según el punto 14 .

El documento, breve, en forma de declaración, contenía un valioso mensaje político-social donde se esgrimían las líneas por las que el nuevo Estado debería ser regulado conforme a los principios de soberanía, igualdad ciudadana y tradición católica. Se trataba de una declaración para la transmisión de la soberanía de los territorios de la Capitanía de Guatemala desde la Corona de España a los pueblos que la integraban. El Acta de Independencia de Centroamérica era significativamente diferente a la Declaración de Independencia de los Estados Unidos de América del 4 de julio de 1776, aunque existan elementos teleológicos comunes. ${ }^{10}$ Esta es una Declaración de confrontación con la metrópoli ${ }^{11}$, mientras que el Acta de Guatemala es una declaración de colaboración entre los representantes del poder de la metrópoli y el pueblo, que reclama su independencia. Además, en la Declaración norteamericana se declara "que todos los hombres son creados iguales", enunciado que después se revelaría, era una proclama falsa, al seguir existiendo la esclavitud; mientras que en el Acta

10 Una versión en español de la Declaración de Independencia de los Estados Unidos de América, puede consultarse en la Biblioteca Jurídica Virtual del Instituto de Investigaciones Jurídicas de la UNAM. www.juridicas.unam.mx.

11 En el texto de la Declaración estadounidense se enfatiza en el hecho de que "La historia el actual Rey de la Gran Bretaña es una historia de repetidos agravios y usurpaciones, encaminados todos directamente hacia el establecimiento de una tiranía absoluta sobre estos Estados". Declaración de Independencia de los Estados Unidos de América, op. cit. p. 210. 
de Independencia de Centroamérica se menciona, expresamente, el principio de la no discriminación en su punto 4 al hablar del número de diputados que deben formar parte del Congreso: "Que el número de éstos Diputados sea en proporción de una por cada quince mil individuos, sin excluir de la ciudadanía a los originarios de África".

Los firmantes del Acta de Independencia de Centroamérica fueron Gabino Gainza, José Matías Delgado, Manuel Antonio Molina, Mariano de Larrave, Mariano de Aycinena, Pedro de Arrollave, José Mario Calderón, Antonio de Rivera, Isidoro del Valle y Castriciones, José Domingo Diéguez, como Secretario de Palacio, y Lorenzo de Romaña como Secretario del Acta ${ }^{12}$.

\subsection{Anexión al Imperio mexicano}

México, como heredero de la Nueva España, había logrado la independencia de España tras una guerra que se inició el 16 de septiembre de 1810. La situación en España durante el período de los infames reyes Carlos IV y Fernando VII, además de la invasión de la península ibérica por Napoleón Bonaparte, motivaron a la sociedad mexicana para buscar el camino de la independencia de la metrópoli, como había sucedido con el vecino anglosajón del norte. Con el nombramiento del hermano de Napoleón, José I, como rey de España, el Ayuntamiento de México reclamó la soberanía con el apoyo del virrey José de Iturrigaray, quien encontró una dura reacción. Tras varias conjuras y conspiraciones, el cura Miguel Hidalgo y Costilla ${ }^{13}$ llamó a la sublevación armada de los campesinos y aborígenes al grito de Dolores, población de Guanajuato. A estos hechos sucedieron otros del mismo cariz protagonizados por José María Morelos y Pavón, quien reunió el Congreso de Anáhuac y continuó el enfrentamiento contra el gobierno colonial.

La adopción de la Constitución de Cádiz, el 19 de marzo de 1812, y el pronunciamiento del coronel Rafael Riego, el 1 de enero de 1820, en Cabezas de San Juan aceleró el ritmo de los acontecimientos en las colonias españolas en América y el acercamiento de los criollos a las tesis independentistas. El general realista Agustín de Iturbide y Aramburu, en un principio, combatió a los insurgentes dirigidos por el militar afro-mexicano Vicente Guerrero, con quien se alió en

12 En otras fuentes se incluyen además de los firmantes señalados los siguientes: Mario de Beltranena, José Antonio de Larrave, José Cecilio del Valle y Pedro Molina.

13 Miguel Gregorio Antonio Ignacio Hidalgo y Costilla Gallaga Mandarte y Villaseñor (1753-1811) fue un sacerdote y militar que protagonizó el Grito de Dolores, el 15 de septiembre de 1810, dando inicio a la rebelión y Guerra de Independencia de México contra el poder español sumiso al rey impuesto por los franceses en España, José I. Fue juzgado y murió fusilado. 
el Abrazo de Acantempan y establecieron el Plan de Iguala ${ }^{14}$, lo que condujo a la independencia de Nueva España, el 27 de septiembre de 1821, con el apoyo de los estamentos sociales y religiosos, tras la firma de los Tratados de Córdoba con Juan O’Donojú. El nuevo territorio, ya independiente, se transformó en el Imperio mexicano en mayo de 1822 proclamando a Agustín de Iturbide emperador, pero en diciembre de 1822, Antonio López de Santa Anna, promulgó el plan Veracruz, con el que derrocaron a Iturbide y establecieron una República, en 1823, tras el Plan de Casa Mata. España reconoció la independencia de México en 1836, después del fallecimiento del infame rey español Fernando VII. Esta era la convulsa situación que existía en esa época.

Las Provincias de Centroamérica habían declarado su independencia de la Corona española el 15 de septiembre de 1821 y el general Agustín de Iturbide les ofreció apoyo para que se consolidara su independencia, proponiendo la unión a México, opción que no era compartida por todas las autoridades de los territorios centroamericanos. Guatemala se manifestó proclive a la unión al Imperio mexicano al que Chiapas, Honduras y Nicaragua ya se habían sumado, adhiriéndose al Plan de Iguala. El general Gabino Gainza informó a Iturbide, el 5 de enero de 1822, que el resultado del escrutinio en la consulta propuesta fue favorable a la unión con México, aunque San Salvador no compartía dicha propuesta, produciéndose algunos enfrentamientos con los opositores a la unión, incluso la ruptura de relaciones entre México y Guatemala, dando lugar a una guerra civil.

La unión se formalizó mediante el Acta de la Unión de la Provincias de Centro América al Imperio mexicano, firmada en el Palacio Nacional de Guatemala el 5 de enero de 1822 (Arriola, 2009: p. 9 y ss). Se menciona la consulta popular y a la propuesta de Iturbide del 19 de octubre y se cita que, 104 ayuntamientos han consentido tal unión con México, así como los que han presentado alguna objeción o condiciones, se concluyó que la unión era favorable por mayoría absoluta de la población, sin contar las provincias ya adheridas desde la independencia de España, como Nicaragua, Comayagua y la de la Ciudad Real de Chiapas, Quezaltenango, Sololá y otros pueblos que tomaron antes la decisión. Incluso, en el texto se alega que la unión es garantía del respeto a los derechos anteriormente existentes y su integridad territorial. ${ }^{15}$

14 El Plan de Iguala se promulgó el 24 de febrero de 1821 consumándose la reunificación de las fuerzas realistas con las insurgentes y constituyendo el Ejército Trigarante que, al entrar en Ciudad de México se afirmó la independencia

15 El texto dice concretamente "Entre las varias consideraciones que ha hecho la Junta, en esta importante y grave materia, en que los pueblos se hayan amenazados en su reposo, y especialmente en la unión con sus hermanos de las otras provincias con quienes ha vivido siempre ligados por la vecindad, comercio y otros vínculos estrechos, fue una de las primeras que por medio de la unión a México querían salvar la integridad de lo que antes se ha llamado Reino de Guatemala, y restablecer 
Además, el Acta de anexión especifica el carácter voluntario de dicha unión con México y se incluye una especie de cláusula de autodeterminación para que en el futuro pudieran declararse independientes, lo que constituye una novedad en el llamado derecho internacional americano. El final del Acta incluye las medidas para su difusión y conocimiento y la relación de los firmantes del documento. La Gaceta de México publicó un "Editorial vaticinando que las provincias de Centro América se unirán a México" y que estaba redactado en un armonioso lenguaje: "Las demás provincias del florido reino de Guatemala, penetradas de cuanto les interesa agregar al grande Imperio Mexicano para poder progresar..." (Heliodoro, 1927a; p. 9). Y, de forma curiosa, el 25 de octubre de 1821 "James Smith Wilcox, más tarde Cónsul de los Estados Unidos en la ciudad de México, anuncia al Secretario de Estado John Quince Adams la independencia de Guatemala y el deseo de ésta de unirse al Imperio Mexicano" (Heliodoro, 1927b; p. 9). El interés de la naciente potencia estadounidense por los asuntos de América Central comenzaba a desvelarse, en especial por la ambición expansionista, cuyos efectos serían sufridos, principalmente, por su vecino, a quien arrebataría la mitad de su territorio.

En 1823 la Asamblea Nacional Constituyente convocó una reunión para modificar la estructura política de Centroamérica, al adoptar la decisión de constituirse en las Provincias Unidas de Centro América, con un gobierno de republica federal, independiente de México, aunque esta fórmula no tuvo éxito y la región se vio sumida en un caos político y económico debido a los intereses locales; crisis que se extendió hasta mediados del siglo XIX.

\subsection{La Declaración de independencia absoluta}

La reunión convocada en Guatemala por la Asamblea Nacional Constituyente adoptó la Declaración de Independencia absoluta de Centroamérica el 1 de julio de 1823, al modificar el estatuto político existente y proclamar las Provincias Unidas de Centro América, al proponer un Congreso de las Provincias para marzo de 1823 y consumar la secesión del Imperio mexicano tras la abdicación de Agustín I como emperador de México el 19 de marzo. El Congreso fue convocado por el Capitán General de Guatemala, Vicente Filísola, el 29 de mayo de 1823. El 2 de octubre fue ratificada en Guatemala el Acta de Independencia absoluta con la presencia de todos los diputados, ya que en la reunión del 1 de julio estuvieron ausentes los diputados de Costa Rica, Honduras y Nicaragua.

entre si la unión que ha reinado por lo pasado; no apareciendo otro para remediar la división que se experimenta". (Arriola, 2009: p. 9 y ss) 
La Declaración de Independencia absoluta de Centroamérica se refiere al Decreto Legislativo de la Asamblea Nacional Constituyente del 1. ${ }^{\circ}$ de julio de 1823 (Menéndez, 1855) y consta de tres declaraciones precedidas de dos consideraciones en las que los reunidos manifiestan y reiteran el deseo de independencia y libertad frente a cualquier Estado extranjero y alude expresamente al español y al mexicano. En la primera parte, la Declaración se remite a otros documentos surgidos de anteriores congresos o asambleas, en especial a la reunión del 15 de septiembre de 1821, renovada el 29 de marzo "con el importante objeto de pronunciar sobre la independencia y libertad de los pueblos" y el acta de 5 de enero de 1822. También se hace referencia al Acta de Independencia de la Intendencia de San Salvador, del 21 de septiembre de 1821.

La primera consideración trae a colación el período que unió los territorios de Centroamérica a la Corona española, lo que apela a las circunstancias imperantes, a la influencia de las corrientes filosóficas, a la distancia y a la condición de colonia de las tierras americanas. Aunque utiliza un léxico propio de la época, muy próximo al de la Declaración de Independencia de los Estados Unidos de América, revela la sólida unión de ambos pueblos situados en las orillas opuestas del océano Atlántico: "Que la experiencia de más de trescientos años manifestó á la América que su felicidad era del todo incompatible con la nulidad a que la reducía la triste condición de colonia de una pequeña parte de Europa" (Menéndez, 1855). A veces resulta incomprensible el sentimiento que el texto desea transmitir pues, como se ha explicado en otro lugar, fue el estamento criollo y eclesiástico, quienes ostentaron ese gobierno colonial y el acta de 15 de septiembre de 1821 es un texto conciliador. Los abusos de los representantes de la Corona quedan denunciados en el párrafo cuarto: "Que la arbitrariedad, con que fue gobernada por la Nación Española, y la conducta que ésta observó constantemente, desde la conquista, excitó en los pueblos él más ardiente deseo de recobrar sus derechos usurpados" (Menéndez, 1855).

En la segunda de las consideraciones, la Declaración de Independencia absoluta se refiere a la efímera unión con el Imperio mexicano y la describe como:

una expresión violenta, arrancada por medios viciosos e ilegales". Y añade que "la expresada agregación ha sido y es contra los intereses y los derechos sagrados de los pueblos, nuestros comitentes que es opuesta á su voluntad; y que un concurso de circunstancias tan poderosas e irresistibles exigen que las Provincias del antiguo Reino de Guatemala se constituyan por sí mismas y con separación del Estado Mexicano. (Menéndez, 1855) 
Las tres declaraciones ${ }^{16}$ que incluyen el Decreto Legislativo de la Asamblea Nacional Constituyente de $1 .^{\circ}$ de julio de 1823 , condensan el deseo de libertad e independencia de cualquier potencia extranjera. El Imperio mexicano había desaparecido y el Imperio español en América había colapsado y era incapaz de poder intervenir en la América continental, a pesar de que prestó apoyo a Napoleón III en su aventura en México, imponiendo a Maximiliano I en el trono de México, que terminó con su fusilamiento en 1867. Así, los responsables de la redacción de las declaraciones no pudieron adivinar que las amenazas contra la soberanía centroamericana que postulaban los asistentes vendrían de Estados Unidos. La Declaración de Independencia termina con la orden de su publicación y comunicación a los destinatarios de Guatemala, León, Granada, Costa Rica y Chiapas, así como a los Gobiernos de España, México y otros Estados de las Américas.

\section{La influencia de Estados Unidos de América}

La Declaración de Independencia de las Trece Colonias de América, del 4 de julio de 1776, tuvo una influencia indudable en la independencia de las colonias del resto de América. Sin embargo, no se puede sostener que esta influencia indujera a los firmantes del Acta de Independencia de Centroamérica en su redacción pues esta es más igualitaria que la Declaración norteamericana. Para observar esta discrepancia se señala el texto de la Declaración de julio de 1776:

...que todos los hombres son creados iguales; que son dotados por su Creador de ciertos derechos inalienables, entre los cuales están la vida, la libertad y la búsqueda de la felicidad; que para garantizar estos derechos se instituyen entre los hombres los gobiernos, que derivan sus poderes legítimos del consentimiento de los gobernados... (Declaración de Independencia de los Estados Unidos de América, s. f.) ${ }^{17}$

16 El texto de las tres declaraciones del Decreto Legislativo de la Asamblea Nacional Constituyente reunida el $1 .^{\circ}$ de julio dice: $1^{\circ}$ Que las expresadas Provincias, representadas en esta Asamblea, son libres e independientes de la antigua España, de México y de cualquiera otra potencia así del antiguo, como del Nuevo Mundo; y que no son ni deben ser el patrimonio de persona ni familia alguna.

$2^{\circ}$ Que, en consecuencia, son y forman Nación Soberana, con derecho y actitud de ejercer y celebrar cuantos actos, contratos y funciones ejercen y celebran los otros pueblos libres de la tierra.

$3^{\circ}$ Que las Provincias sobredichas, representadas en esta Asamblea (y las demás espontáneamente se agreguen de las que componían el antiguo Reino de Guatemala), se llamarán, por ahora, y sin perjuicio de lo que se resuelva en la Constitución que ha de formarse, "PROVINCIAS UNIDAS DEL CENTRO DE AMÉRICA”. (Menéndez, 1855)

17 Declaración de Independencia de los Estados Unidos de América. Una versión en español puede consultarse en la Biblioteca Jurídica Virtual del Instituto de Investigaciones Jurídicas de la UNAM. www.juridicas.unam.mx, p. 209. 
Resulta evidente que la Declaración estadounidense no tuvo una influencia plena en el texto del Acta de Independencia de Centroamérica pues esta menciona expresamente la no discriminación racial, lo que en el documento de 1776 no era evidente. Además, era un documento de confrontación no solo con la monarquía británica, sino que se observa un reproche a todo el pueblo de Gran Bretaña, al que califica de "nuestros hermanos británicos" y no duda en culparles de que "han sido sordos a la voz de la justicia y la consanguinidad" y mediatiza su juicio con una declaración lapidaria: "enemigos en la guerra, amigos en la paz". Por lo tanto, la influencia de la independencia de Estados Unidos es visible pero no un modelo a seguir, independientemente de que, a posteriori, las nuevas repúblicas adopten una organización política similar a la de Estados Unidos.

Desde 1630, en lo que hoy es Estados Unidos, venía produciéndose la expansión de los colonos hacia el Oeste. El pastor John Cotton había propagado su visión de que la providencia divina les había llamado a poblar los territorios desde el este. En 1803, cuando Napoleón Bonaparte era Primer Cónsul de Francia, Thomas Jefferson compró a Francia el territorio de la Luisiana, ${ }^{18}$ con el fin de acceder a las costas del golfo de México, a través del río Mississippi y eliminar el muro de contención a la política expansionista. La visión geoestratégica de Jefferson facilitó el gran objetivo de Estados Unidos: ampliar su territorio hasta el océano Pacífico.

En 1823, Centro América se encontraba todavía celebrando su independencia de España, pero estaba sumida en una gran inestabilidad política y social. No es pura casualidad que el presidente James Monroe dirigiera el 2 de diciembre de 1823 un mensaje al Congreso de Estados Unidos, que se conoce como la "Doctrina Monroe", cuyo objetivo era mucho más profundo que el alegato de "América para los americanos" que se comprende cuando Estados Unidos se autocalifica de América.

En realidad, el mensaje del presidente estadounidense tiene que ser considerado en el marco de la política expansionista de Estados Unidos. Aunque la declaración menciona, de forma expresa al Imperio ruso y al británico, las consecuencias de la política exterior norteamericana llegarían hasta Centroamérica y el

18 Luisiana era un territorio de más de dos millones de kilómetros cuadrados situado al oeste del río Mississippi, que perteneció a la Capitanía General de Cuba, como parte del Virreinato de Nueva España, desde el Tratado de París de 1763, y devuelta a Francia en 1803. Napoleón Bonaparte lo vendió a Estados Unidos en 1803, violando los acuerdos de retroventa, por 15 millones de dólares. Comprendía los territorios de los actuales Estados de Arkansas, Iowa, Kansas, Okahoma, Minesota, Misuri, Nebraska y gran parte de las Dakotas, además de franjas de los Estados de Montana, Nuevo México, Texas, Wyoming y Luisiana. 
Caribe $^{19}$. En 1845 el editor y periodista político John Louis O'Sullivan utilizó el término de "manifest destiny" para promover la anexión de Texas y de los territorios del Oregón, constituyéndose en uno de los pilares de la política exterior de Estados Unidos. La nueva estrategia era arrebatar a México los territorios que dificultaban este propósito y encontrar una vía de comunicación en el istmo centroamericano que permitiera a sus buques alcanzar las costas del Pacífico.

\section{Conclusiones}

La independencia de los territorios de la antigua Capitanía General de Guatemala tuvo manifestaciones diversas en las dos declaraciones de independencia. La primera con el Acta de Independencia de Centroamérica, del 15 de septiembre de 1821, en la que se produce la separación de la monarquía española, se trata más bien de un convenio pacífico de traspaso de la soberanía con la participación de los representantes de las autoridades coloniales.

Sin embargo, la segunda, la Declaración de Independencia absoluta de Centroamérica por el Decreto Legislativo de la Asamblea Nacional Constituyente, del $1 .^{\circ}$ de julio de 1823 , es más bien una manifestación más próxima a la Declaración de Independencia de Estados Unidos. Entre ambas se producen otras manifestaciones que afectaban a la independencia y a la soberanía real de las posteriormente llamadas Provincias Unidas de Centroamérica, en especial, el Acta de Anexión de Centro América al Imperio mexicano, del 5 de enero de 1822.

Se ha examinado la evolución del proceso revolucionario pacífico que condujo a la independencia de las Provincias de Centroamérica, pues no hubo enfrentamientos importantes entre los independentistas y la metrópoli española o México. Bien es verdad que se produjeron algunas tensiones provocadas por la falta

19 Por su interés, se transcribe en idioma original parte del discurso del presidente James Monroe: “...At the proposal of the Russian Imperial Government, made through the minister of the Emperor residing here, a full power and instructions have been transmitted to the minister of the United States at St. Petersburg to arrange by amicable negotiation the respective rights and interests of the two nations on the northwest coast of this continent. A similar proposal has been made by His Imperial Majesty to the Government of Great Britain, which has likewise been acceded to. The Government of the United States has been desirous by this friendly proceeding of manifesting the great value which they have invariably attached to the friendship of the Emperor and their solicitude to cultivate the best understanding with his Government. In the discussions to which this interest has given rise and in the arrangements by which they may terminate the occasion has been judged proper for asserting, as a principle in which the rights and interests of the United States are involved, that the American continents, by the free and independent condition which they have assumed and maintain, are henceforth not to be considered as subjects for future colonization by any European powers..." (U. S. National Archives \& Records Administration, s. f.). 
de unanimidad en la adopción de las decisiones que afectaban a la soberanía, como la producida a consecuencia de la actitud de San Salvador ${ }^{20}$ y unos pocos incidentes que solo quedaron en simples declaraciones violentas.

El profesor e historiador Pierre Renouvin expone, de manera acertada, sus tesis sobre la situación geoestratégica en el Caribe como consecuencia de la independencia de las colonias españolas en el continente americano, lo anterior, al explicar las verdaderas intenciones de las potencias europeas y de Estados Unidos en el Caribe y en Centroamérica, en perjuicio de los intereses de los territorios de América Central y de su legítima soberanía.

De esta manera, quedaron ya lejanas las buenas intenciones de las Declaraciones de Independencia de los territorios de América Central donde independencia y soberanía no necesariamente eran las dos caras de una misma moneda. Todo era cuestión de tiempo.

\section{Referencias}

(1962). "La Entrevista de Guayaquil”; Reportaje de la Historia. Editorial Planeta, Barcelona.

Arriola, J. (2009). Acta de Anexión de Centro América al Imperio Mexicano. Diccionario Enciclopédico de Guatemala.

Atlas Histórico del Mundo. (2011). La Independencia de América Latina. Tikal, Susaeta Ediciones, Madrid.

Diccionario Enciclopédico Salvat. (1981). Salvat Universal, Tomo 2, Barcelona.

Heliodoro V., R. (Comp.) (1927a). Archivo Histórico Diplomático Mexicano. La anexión de Centro América a México. Documentos y escritos de 1821-1822. Tomo II. Publicaciones de la Secretaria de Relaciones Exteriores, México 1927a, Doc. N. ${ }^{\circ}$ I, de 4 de octubre de 1821,

Heliodoro V., R. (Comp.). (1927b). Archivo Histórico Diplomático Mexicano. La anexión de Centro América a México. Documentos y escritos de 1821-1822. Tomo II. Publicaciones de la Secretaria de Relaciones Exteriores, México 1927b, Doc. N. ${ }^{\circ}$ II, de 25 de octubre de 1821.

20 Así se recoge en la crónica de 5 de febrero de 1822, con el Num. XXXI, en el que se informa que "El presidente de la Diputación Provincial de San Salvador, Dr. José Matías Delgado, se dirige al Jefe Político Subalterno de Sonsonete, don Juan Fermín Aycinema, anunciándole la resolución de resistir por la fuerza a Guatemala" en: La anexión de Centro América a México. Documentos y escritos de 1821-1822. Tomo II. Archivo Histórico Diplomático Mexicano, p. 45. 
Menéndez, I. (1855). Declaración de Independencia absoluta de Centroamérica. Decreto Legislativo de la Asamblea Nacional Constituyente del $1 .^{\circ}$ de julio de 1823; Recopilación de las Leyes del Salvador en Centroamérica. http://www.redicces.org.sv/jspui/handle/10972/1621

Miaja de la Muela, A. (1968). La Emancipación de los pueblos coloniales y el Derecho Internacional, Editorial Tecnos, Madrid.

Potthast-Jutkeit, B. (1998). Centroamérica y el contrabando por la Costa de los Mosquitos en el siglo XVIII. Mesoamérica.

Renouvin, P. (1982 y 1990). Historia de las Relaciones Internacionales, Siglos XIX y XX. Akal, Madrid.

Sánchez A., L. (1971). Derecho Constitucional comparado. Mundo Científico. Serie Jurídica. Editora Nacional, Madrid.

U. S. National Archives \& Records Administration. (s. f.). Transcript of Monroe Doctrine. https://www.ourdocuments.gov/print_friendly.php?flash $=$ false $\&$ page $=$ transcript $\&$ doc $=23 \&$ title $=$ Transcript + of + Monroe + Doctri ne $+\% 281823 \% 29$

Vicens V., J. (1976). Historia General Moderna. Montaner y Simón, S. A., Barcelona. 
